\title{
Modelling Moho depth in ocean areas based on satellite altimetry using Vening Meinesz-Moritz' method
}

\author{
M. Abrehdary ${ }^{1}$ L. E. Sjöberg ${ }^{1}$ M. Bagherbandi ${ }^{1,2}$
}

Received: 16 November 2014/ Accepted: 23 April 2015/Published online: 12 May 2015

(C) Akadémiai Kiadó 2015

\begin{abstract}
An experiment for estimating Moho depth is carried out based on satellite altimetry and topographic information using the Vening Meinesz-Moritz gravimetric isostatic hypothesis. In order to investigate the possibility and quality of satellite altimetry in Moho determination, the DNSC08GRA global marine gravity field model and the DTM2006 global topography model are used to obtain a global Moho depth model over the oceans with a resolution of $1^{\circ} \times 1^{\circ}$. The numerical results show that the estimated Bouguer gravity disturbance varies from 86 to $767 \mathrm{mGal}$, with a global average of $747 \mathrm{mGal}$, and the estimated Moho depth varies from 3 to $39 \mathrm{~km}$ with a global average of $19 \mathrm{~km}$. Comparing the Bouguer gravity disturbance estimated from satellite altimetry and that derived by the gravimetric satellite-only model GOGRA04S shows that the two models agree to $13 \mathrm{mGal}$ in root mean square (RMS). Similarly, the estimated Moho depths from satellite altimetry and GOGRA04S agree to $0.69 \mathrm{~km}$ in RMS. It is also concluded that possible mean dynamic topography in the marine gravity model does not significantly affect the Moho determination.
\end{abstract}

Keywords Vening Meinesz-Moritz $\cdot$ Moho depth · Satellite altimetry · DNSC08GRA

\section{Introduction}

One of the primary interfaces of the Earth interior is the boundary between the crust and mantle, which is called the Mohorovičić discontinuity (or shortly Moho). This boundary can be determined by means of seismic and/or gravimetric methods, where the former is based on observations of seismic wave refraction at the crust-mantle discontinuity, and the latter is based

M. Abrehdary

majidab@kth.se

1 Division of Geodesy and Satellite Positioning, Royal Institute of Technology (KTH), 10044 Stockholm, Sweden

2 Department of Industrial Development, IT and Land Management, University of Gävle, 80176 Gävle, Sweden 
on observations of the gravitational effect due to the density contrast caused by the different composition of crust and mantle. Much research using seismic surveys to estimate the global crust-mantle boundary has been made in the last decades. For example, Shapiro and Ritzwoller (2002) and Meier et al. (2007) compiled global Moho models based purely on seismic data analysis, and Lebedev et al. (2013) estimated the Moho depth using seismic surface waves. For global studies the most frequently used crustal models are the CRUST2.0 (Bassin et al. 2000) and CRUST1.0 model, the latter compiled with a $1 \times 1$ arc-degree spatial resolution. Over large areas of the world with a sparse coverage of seismic data, a gravimetric-isostatic or combined gravimetric/seismic method is used. Vening Meinesz (1931) modified the AiryHeiskanen theory (see, Heiskanen and Moritz 1967, Sects. 3 and 4) by introducing a regional isostatic compensation model based on a thin plate lithospheric flexure model (see Watts 2001, p. 114). Moritz (1990, Sect. 8) generalized the Vening Meinesz gravimetric isostatic hypothesis from a regional to global compensation. Sjöberg (2009) reformulated Moritz' problem, hereafter called the Vening Meinesz-Moritz (VMM) problem of isostasy, as that of solving a nonlinear Fredholm integral equation of the first kind. He also presented a second-order solution which we will present in Eq. (3) and later apply numerically. Sampietro et al. (2014) developed a method for Moho recovery using GOCE gravity gradient data; see also Bouman et al. (2013). Reguzzoni and Sampietro (2014) estimated the Moho depth using the combination of the CRUST1.0 and a GOCE global gravity models; see also Reguzzoni et al. (2013).

Nowadays, a huge improvement is observed in the accuracy and spatial resolution of global marine gravity field models, which are achieved by using various new data, like gravimeters onboard marine vessels (e.g., ships and submarines), onboard aircrafts, and, finally, from satellite altimetry. Marine gravity disturbances can be deduced from satellite radar altimetry, where the measured and time-averaged sea surface height ( $\mathrm{SSH}$ ) can be converted to gravity using a variety of inverse methods (Deng et al. 2011). The benefit of altimeter-derived marine gravity disturbances is that they are derived from relatively homogeneous data coverage and several different satellite missions can be merged to obtain a high resolution marine gravity field model (cf. Hwang and Parsons 1996 and Deng et al. 2011). They are also not subject to drift- and navigation-based errors. Therefore, the above mentioned advantages for satellite altimetry data motivated the present study to use satellite altimetry to estimate Moho depth over the oceans based on the VMM hypothesis. For this purpose the new DNSC08GRA global marine gravity field model (Andersen et al. 2010) is applied. As the observed gravity field contains nuisance signals from the topography and density heterogeneities related to bathymetry, ice, sediments, and other crustal components, these signals are sequentially removed by applying so-called stripping corrections (Tenzer et al. 2014). In this context, when the global marine gravity field model by satellite altimetry is used for recovery of the Moho depth, our question is related with the problem of determining the marine gravity field model from satellite altimetry. This problem is related with the mean dynamic topography (MDT), which yields a systematic error to the result. In Sects. 4.2 and 4.3 we study whether it significantly affects the Moho and geoid modelling.

\section{Method}

\subsection{Vening Meinesz-Moritz' model}

Based on Sjöberg (2009) and (2013) the VMM inverse problem of isostasy is to determine the Moho depth such that the isostatic compensating attraction $A_{C}(P)$ of the crustal mass 
totally compensates the Bouguer gravity disturbance on the Earth's surface, implying that the isostatic gravity disturbance $\delta g_{I}(P)$ vanishes for point $P$ on the Earth's surface:

$$
\delta g_{I}(P)=\delta g_{B}(P)+A_{C}(P)=0 .
$$

Here $\delta g_{B}(P)$ is the Bouguer gravity disturbance corrected for the gravitational contributions of topography/bathymetry and density contrasts of the oceans, ice and sediments (Bagherbandi et al. 2013). The VMM problem, based on Eq. (1), can be formulated by the non-linear integral equation

$$
R \iint_{\sigma} K(\psi, s) d \sigma=f(P)
$$

where

$$
K(\psi, s)=\sum_{n=0}^{\infty} \frac{n+1}{n+3}\left(1-s^{n+3}\right) P_{n}(t)
$$

is the kernel function of the integral, $R$ is the mean earth radius, $\sigma$ is the unit sphere, $t$ is $\cos \psi, \psi$ is the geocentric angle, $P_{n}(t)$ is the $n$-th Legendre's polynomial, $s(=1-T / R)$ is a simple function of the Moho depth $T$, which is the unknown of the integral equation. The isostatic gravity disturbance functional $f$ is given by

$$
f(P)=-\frac{1}{G \Delta \rho}\left[\delta g_{B}(P)+A_{C 0}(P)\right]
$$

where $G$ is Newton's gravitational constant, $\Delta \rho$ is the Moho density contrast, and $A_{C 0}\left(=-4 \pi G \Delta \rho T_{0}\right)$ is the nominal compensation attraction with $T_{0}$ as the nominal Moho depth. For solving Eq. (2a), $f(P)$ is expanded in a series of fully normalized spherical harmonics

$$
f(P)=\sum_{n=0}^{\infty} \sum_{m=-n}^{n} f_{n m} Y_{n m}(P),
$$

where $Y_{n m}(P)$ is the fully-normalized spherical harmonic of degree $n$ and order $m$. The coefficients $f_{n m}$ of Eq. (4a) are obtained by:

$$
f_{n m}=\left\{\begin{array}{l}
{\left[\left(\delta g_{B}\right)_{00}-A_{C_{0}}\right] /(4 \pi k), \text { if } n=0} \\
{\left[\left(\delta g_{B}\right)_{n m}\right] /(4 \pi k), \text { otherwise } .}
\end{array}\right.
$$

Here $k$ is $G \Delta \rho$. The first-order solution to the Moho depth becomes

$$
\begin{aligned}
T(P) \approx T_{1}(P) & =\left[2 f(P)-\sum_{n=0}^{\infty} \frac{1}{n+1} \sum_{m=-n}^{n} f_{n m} Y_{n m}(P)\right] \\
& =\sum_{n=0}^{\infty}\left(2-\frac{1}{n+1}\right) \sum_{m=-n}^{n} f_{n m} Y_{n m}(P),
\end{aligned}
$$

and it is used as input to the second-order formula (Sjöberg 2009; Bagherbandi et al. 2013):

$$
T(P)=T_{1}(P)+\frac{T_{1}^{2}(P)}{R}-\frac{1}{32 \pi R} \iint_{\sigma} \frac{T_{1}^{2}(Q)-T_{1}^{2}(P)}{\sin ^{3}(\psi / 2)} d \sigma,
$$


where $P$ and $Q$ are the computation and integration points, respectively. According to this formula, the Moho depth can be improved from the first-order solution.

\section{Description of the data and numerical study}

\subsection{Description of the data}

In this study 42,965 free-air gravity disturbances derived from the DNSC08GRA global marine gravity field model (Andersen et al. 2010) in a set of $1^{\circ} \times 1^{\circ}$ blocks over the oceans were considered. The DNSC08GRA model is provided using a new double retracking technique for analyzing the satellite altimetry. The considered free-air gravity disturbances were used to obtain simple Bouguer gravity disturbance and then it was corrected for the gravitational contributions of topography/bathymetry and density contrasts of the oceans, ice sheets and sediment basins (see Eq. 1) which corrections were derived from the ESCM180 Earth's spectral crustal model (Tenzer et al. 2014). In Sjöberg (2009) Eq. (1) was formulated for the gravity anomaly, but in this paper it is updated for gravity disturbance rather than gravity anomaly. Tenzer and Bagherbandi (2012) showed numerically that the estimated Moho depths from gravity disturbance provide a $24 \%$ better global root mean square (RMS) fit with the seismic Moho depth model CRUST2.0, and Sjöberg (2013) gave a theoretical proof to this result. Another Bouguer gravity disturbance model was generated from the combined GRACE and GOCE gravity model GOGRA04S (Yi et al. 2013) coefficients complete to degree and order 180 of spherical harmonics. The spherical harmonics of the normal gravity field were computed according to the parameters of the reference system GRS-80 (Moritz 2000). The generated Bouguer gravity disturbances were corrected in the same way as above for satellite altimetry.

The global crustal model CRUST1.0 was used to obtain both $\Delta \rho$ and $T_{0}$ for each block. The CRUST1.0 model is specified on a $1^{\circ} \times 1^{\circ}$ grid and it is the result of a comprehensive effort to compile a global model of the Earth's crust and lithosphere, LITHO1.0 (Laske 2013; Pasyanos et al. 2012).

\subsection{Numerical study}

It should be noted that always after correcting the intra-crustal density anomalies (such as those for water, ice and sediment) there are still some density anomalies left in the upper and lower mantle that we call non-isostatic effects (NIEs). This implies that these effects $\left(\delta A_{C}\right)$, should be corrected on the isostatic gravity disturbance $\left(\delta g_{I}\right)$, yielding the pure isostatic gravity disturbance (see Bagherbandi and Sjöberg 2012)

$$
\delta g_{I}(P)=\delta g_{B}(P)+A_{C}(P)+\delta A_{C}(P)=0 .
$$

However, as we do not have information about most of the NIEs, we cannot remove them completely (see Bagherbandi and Sjöberg 2013).

Equation (5b) was applied for the DNSC08GRA global marine gravity field model and the DTM2006 topography model to degree and order 180 to obtain a global Moho depth model over the oceans with a resolution of $1^{\circ} \times 1^{\circ}$. The statistics of the estimated Bouguer gravity disturbance and Moho depths are given in Table 1 .

As seen in the table, the Bouguer gravity disturbance derived from satellite altimetry varies between 86 and $767 \mathrm{mGal}$ with a global average and standard deviation of 474 and $112 \mathrm{mGal}$ 
Table 1 Statistics of the free-air, Bouguer gravity disturbance and Moho depths estimated from satellite altimetry and GOGRA04S models

\begin{tabular}{|c|c|c|c|c|c|c|}
\hline Unit & Quantities & Max. & Mean & Min. & STD & RMS \\
\hline \multirow[t]{6}{*}{$\mathrm{mGal}$} & $\delta g^{\text {Altimetry }}$ & 252.97 & -0.99 & -302.97 & 20.48 & \\
\hline & $\delta g^{\text {Combined Model }}$ & 186.37 & -1.03 & -280.81 & 17.37 & \\
\hline & $\delta g_{B}^{\text {Altimetry }}$ & 767.04 & 474.58 & 85.67 & 112 & \\
\hline & $\delta g_{B}^{\text {Combined Model }}$ & 715.33 & 474.52 & 60.40 & 111.8 & \\
\hline & $\delta g^{\text {Altimetry-Combined Model }}$ & -181.55 & -0.04 & 166.13 & 10.73 & 10.73 \\
\hline & $\delta g_{B}^{\text {Altimetry-Combined Model }}$ & 181.55 & 0.06 & -166.13 & 13.17 & 13.17 \\
\hline \multirow[t]{6}{*}{$\mathrm{km}$} & $T_{1}^{\text {Altimetry }}$ & 39.40 & 18.67 & 3.20 & 5.91 & \\
\hline & $T_{2}^{\text {Altimetry }}$ & 43.18 & 14.73 & 1.14 & 5.52 & \\
\hline & $T^{\text {Combined Model }}$ & 40.64 & 18.70 & 5.94 & 5.92 & \\
\hline & $T^{\text {Altimetry-Combined Model }}$ & 8.80 & -0.003 & -9.62 & 0.69 & 0.69 \\
\hline & $T_{1}^{\text {Altimetry-GEMMA1.0 }}$ & 31.98 & 0.41 & -20.42 & 3.02 & 3.05 \\
\hline & $T_{1}^{\text {Altimetry-CRUST1.0 }}$ & 19.17 & 0.49 & -8.92 & 2.20 & 2.25 \\
\hline
\end{tabular}

$S T D$ standard deviation of the estimated quantities over the ocean blocks, $R M S$ root mean square, $\delta g^{\text {Altimetry }}, \delta g_{B}^{\text {Altimetry }}, \delta g^{\text {Combined Model }}$ and $\delta g_{B}^{\text {Combined Model }}$ are the free-air, Bouguer gravity disturbances and $T_{1}^{\text {Altimery }}, T_{2}^{\text {Altimery }}$ and $T^{\text {Combined Model }}$ are the Moho depths estimated from satellite altimetry (before and after correcting for non-isostatic effects) and GOGRA04S models, respectively

in ocean areas. For evaluating this model, the corresponding Bouguer gravity disturbance derived from the GOGRA04S model was used, showing that the difference varies from -181 to $166 \mathrm{mGal}$, with a global average of $0.06 \mathrm{mGal}$ and a RMS fit of $15 \mathrm{mGal}$. The Moho depths estimated from satellite altimetry and GOGRA04S model differ from -10 to $9 \mathrm{~km}$, with a global average of $-0.003 \mathrm{~km}$ and a RMS fit of $0.69 \mathrm{~km}$. As we already explained above the NIEs should be corrected on the gravity disturbances for estimating accurate Moho depths. Therefore, the corrected Moho depths are compared with those from the GEMMA1.0 and CRUST1.0 models. The GEMMA1.0 model is a global Moho depth model obtained by combination of the CRUST1.0 and a GOCE global gravity models (Reguzzoni and Sampietro 2014). By simple comparison of the corrected Moho depths in this study and the GEMMA1.0 model (Table 1), we find that the differences vary from -20.4 to $31.9 \mathrm{~km}$, with a global average of $0.41 \mathrm{~km}$ and a RMS fit of $3 \mathrm{~km}$. A similar comparison with the independent seismic based CRUST1.0 model (Laske 2013) yields -8.9 to $19.1 \mathrm{~km}$, with a global average and RMS fit of 2.2 and $2.2 \mathrm{~km}$, respectively.

\section{Analysis of the results}

\subsection{General analysis}

This section shows the estimated Bouguer gravity disturbance (Fig. 1) and Moho depths (Figs. 2a, b) estimated from satellite altimetry (before and after correcting NIEs). Figures 3 and 4 show the differences of the Bouguer gravity disturbance and Moho depths derived by GOGRA04S model.

As one can see, the large Bouguer gravity disturbances range to more than $700 \mathrm{mGal}$ in the open ocean areas, while close to the continents they are generally small. 


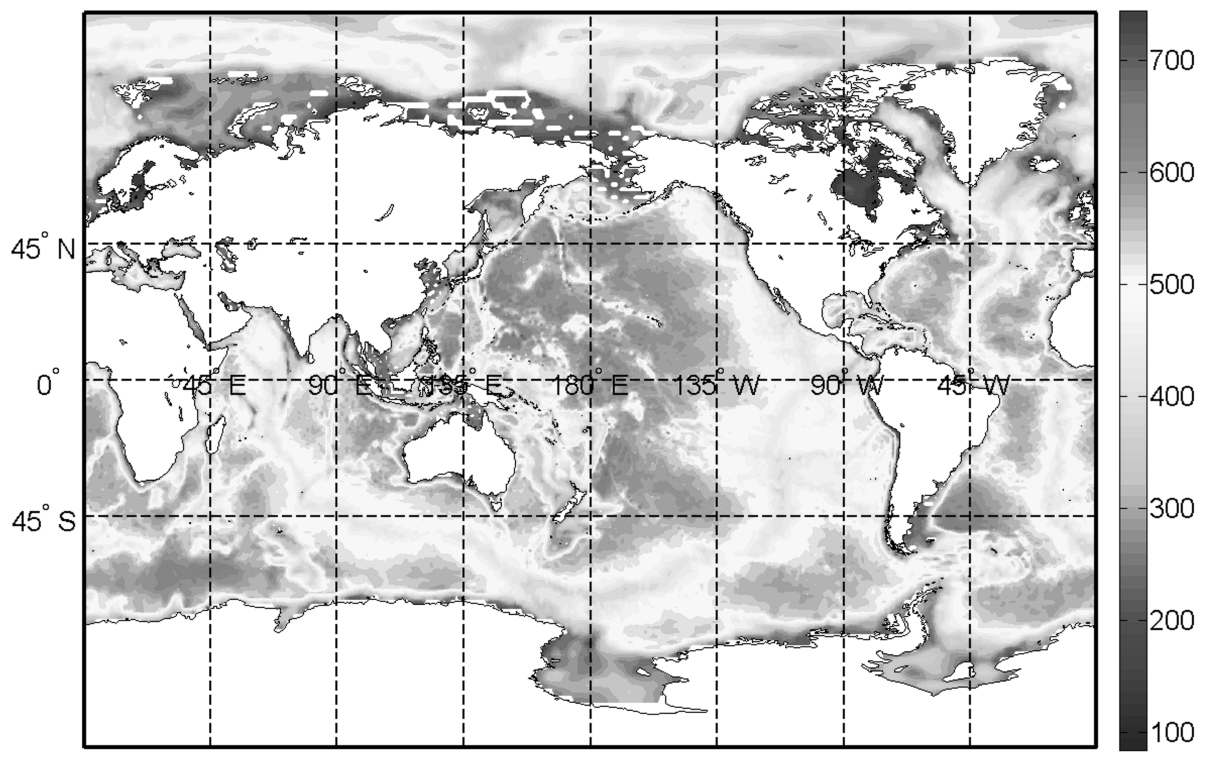

Fig. 1 The Bouguer gravity disturbance estimated from satellite altimetry. (Unit: mGal)

Figure 2a shows that the Moho depths are generally less than $20 \mathrm{~km}$, in the open ocean areas, but increase along the oceanic ridges and to $35 \mathrm{~km}$ towards the continental margins. One probable factor is due to the above mentioned non-isostatic geophysical phenomena (see Bagherbandi and Sjöberg 2012) such as mantle convection. To overcome this problem the NIEs were considered for estimating the crustal thickness properly (Fig. 2b).

As shown in Fig. 2b the corrected Moho depths are generally less than $15 \mathrm{~km}$ in the open ocean areas and along the oceanic ridges, but increase to more than $30 \mathrm{~km}$ towards continental margins.

In Figs. 3 and 4 the estimated Bouguer gravity disturbance and Moho depths are compared by those obtained from the GOGRA04S model. Common to the figures is that the differences of our modelled Bouguer gravity disturbances and Moho depths and those from the GOGRA04S model are most notable along the coastal zones and Polar Regions. One possible reason could be that the quality and coverage of the satellite altimetry data are degraded in those regions, but also by occasionally erroneous retracking in these areas (cf. Andersen et al. 2010).

\subsection{Geoid undulations versus MDT effects}

Nowadays one of the important challenges in oceanography is the accurate determination of the MDT $(\xi)$ which can be obtained by computing the difference between the mean sea surface height $(M S S)$ obtained from satellite altimetry and geoid height $(N)$ derived from a global gravity field model (cf. Andersen et al. 2010):

$$
\xi=M S S-N .
$$

A reference ellipsoid is used to provide the common datum for the MSS and the geoid models. The main aim of this section is to investigate the problem to determine geoid 

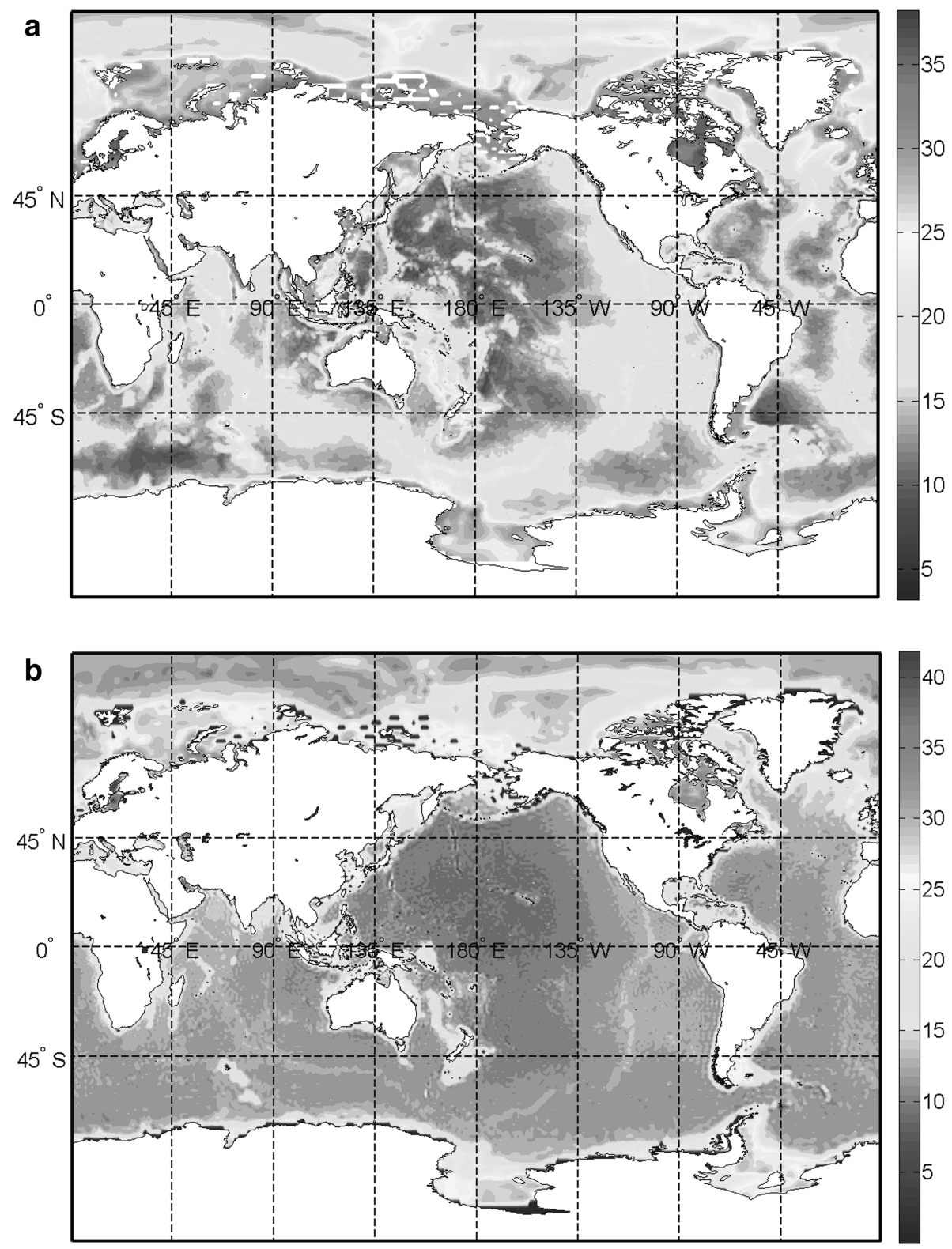

Fig. 2 a The Moho depth estimated from satellite altimetry. (Unit: km). b The corrected Moho depth for non-isostatic effect via satellite altimetry. (Unit: $\mathrm{km}$ )

undulation from satellite altimetry with respect to the MDT effect. This is achieved by comparing the geoid undulations estimated by satellite-only gravimetric and satellite altimetry models to degree and order 50 (cf. Andersen et al. 2010) to figure out the possible presence of the MDT in the altimetric geoid model. It should be noted that the two geoid models must be independent of each other. This implies that the first model must be 


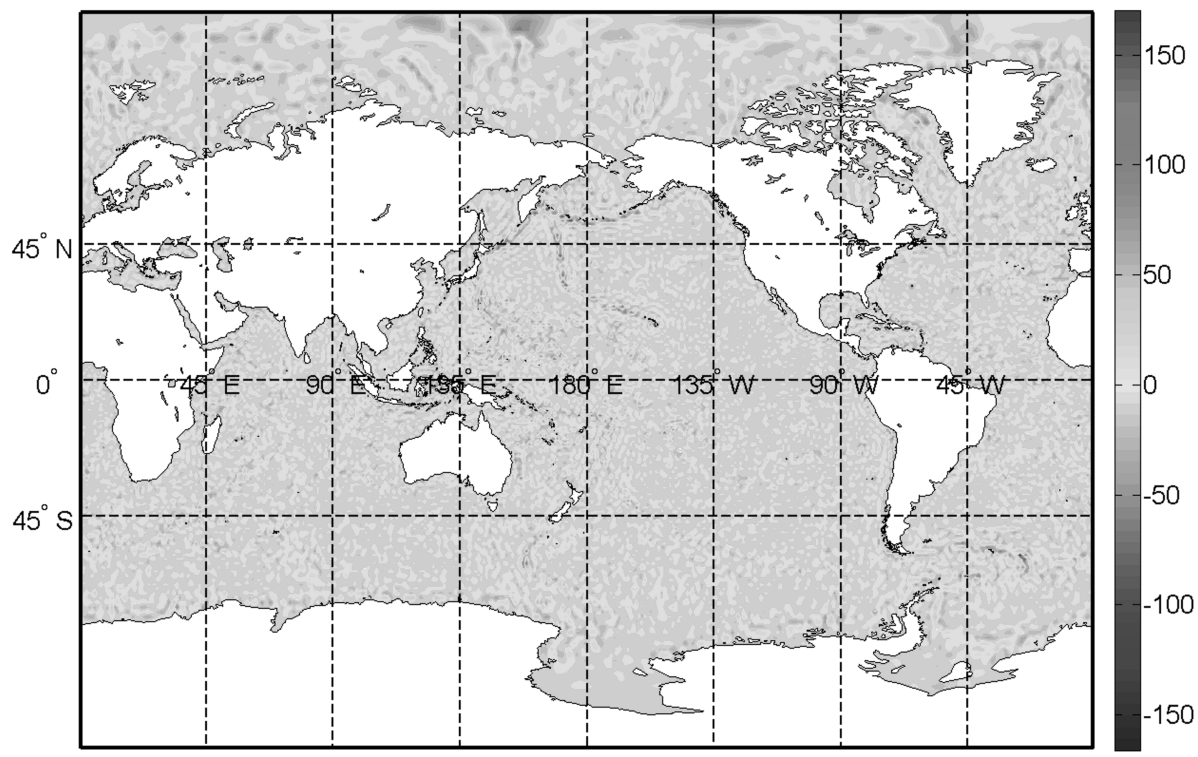

Fig. 3 The difference between the Bouguer gravity disturbances estimated by satellite altimetry and GOGRA04S model. (Unit: mGal)

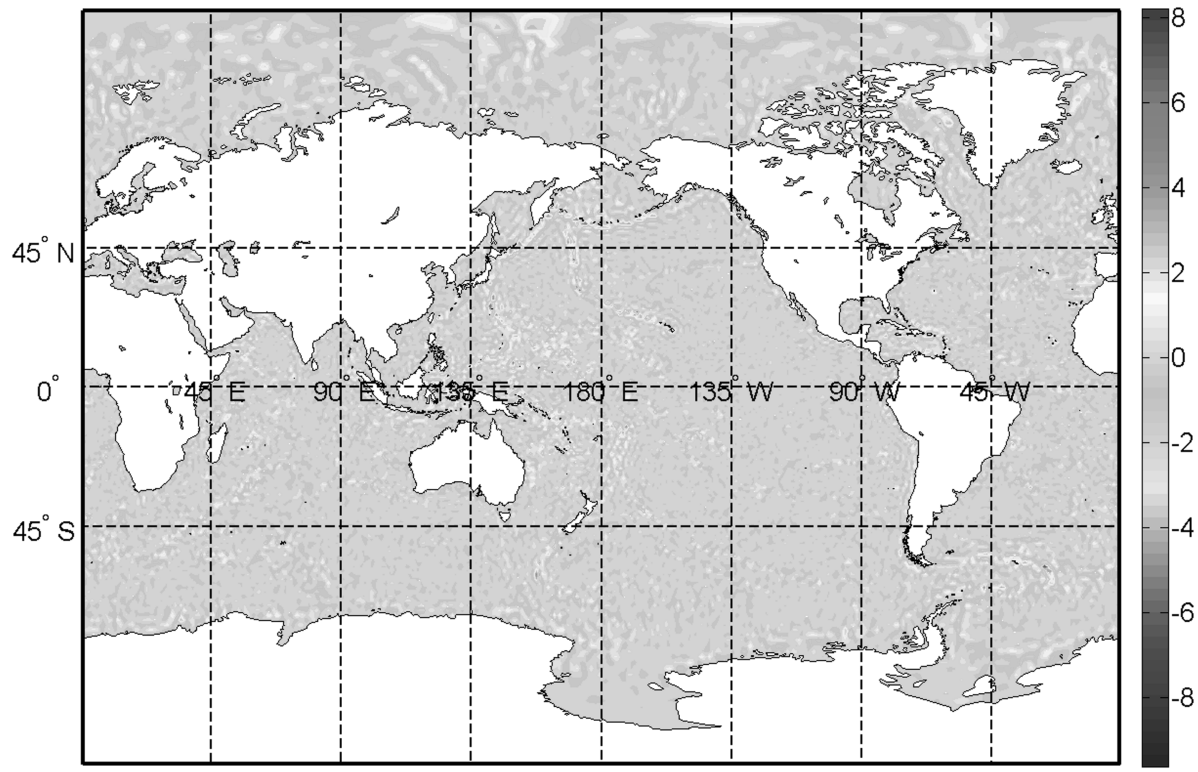

Fig. 4 The difference between the Moho depths estimated by satellite altimetry and GOGRA04S model. (Unit: km)

computed from gravity field models estimated without any altimetry derived surface gravity (Janjić et al. 2012). A satellite-only gravity field model, derived exclusively from the GRACE-GOCE combined model satisfies this condition and avoids the risk that geoid 
heights are corrupted by altimetry. Thus, two geoid height models were computed based on spherical harmonics complete to degree 50: (a) a combined satellite-only model (GOGRA04S) and (b) a model based on the satellite altimetry (DNSC08GRA). The only available information of satellite altimetry for geoid determination in this study is a gravity disturbance grid derived by the DNSC08GRA model. From these data we may directly express altimetry derived gravity disturbance $\left(\delta g^{\text {Altimetry }}\right)$ as a series of Laplace surface harmonics (see, Heiskanen and Moritz 1967, p. 31), analogous to Eq. (4a), as

$$
\delta g^{\text {Altimetry }}(P)=\sum_{n=0}^{\infty} \delta g_{n}^{\text {Altimetry }}(P)=\sum_{n=0}^{\infty} \sum_{m=-n}^{n} \delta g_{n m}^{\text {Altimetry }} Y_{n m}(P),
$$

where

$$
\delta g_{n m}^{\text {Altimetry }}=\frac{1}{4 \pi} \iint_{\sigma} \delta g^{\text {Altimetry }}(Q) Y_{n m}(Q) d \sigma,
$$

Here $\delta g_{n}^{\text {Altimetry }}(P)$ is the gravity disturbance Laplace harmonic of degree $n$. Then the disturbing potential, $S$ (see, Heiskanen and Moritz 1967, p. 88), can be expressed in a Laplace form as

$$
S=\sum_{n=0}^{\infty} S_{n}=R \sum_{n=0}^{\infty} \frac{\delta g_{n}^{\text {Altimetry }}}{n+1} .
$$

Finally, using Bruns' formula (see, Heiskanen and Moritz 1967, p. 85), the geoid undulations are obtained. The statistics of the geoid models estimated from satellite altimetry and GOGRA04S models and their difference are shown in Table 2.

As can be seen from the table, the geoid undulations of the two models initially look more or less identical. However, the estimated RMS difference $0.76 \mathrm{~m}$ may indicate that they differ significantly, which is likely due to the systematic MDT effect.

As seen from Fig. 5 the largest and lowest values of geoid height differences between the two models appear mainly around the Equator, but close to the Pole the lowest values are increased. One factor of this discrepancy could be attributed on one hand to error in the GOGRA04S model and on the other hand to errors in the altimeter data, the adjustment process used to remove systematic errors from the altimeter data caused by orbit error and altimeter bias, the data coverage, the prediction procedure used. Another possible factor is that the MDT is not well corrected in the altimetric data (Rapp 1980).

Table 2 Statistics of the difference between the geoid undulations estimated from satellite altimetry and GOGRA04S models in ocean areas

\begin{tabular}{llrrrrr}
\hline Unit & Quantities & Max. & Mean & Min. & STD & RMS \\
\hline $\mathrm{m}$ & $N^{\text {Altimetry }}$ & 78.37 & 1.23 & -105.68 & 24.57 & \\
& $N^{\text {Combined Model }}$ & 79.64 & 1.29 & -106.13 & 24.70 & \\
& $N^{\text {Altimetry-Combined Model }}$ & 5.86 & -0.03 & -5.96 & 0.76 & 0.76 \\
\hline
\end{tabular}

STD standard deviation of the estimated quantities over the ocean blocks, $R M S$ root mean square, $N^{\text {Altimetry }}$ and $N^{\text {Combined Model }}$ are the geoid undulations estimated by satellite altimetry and GOGRA04S models 


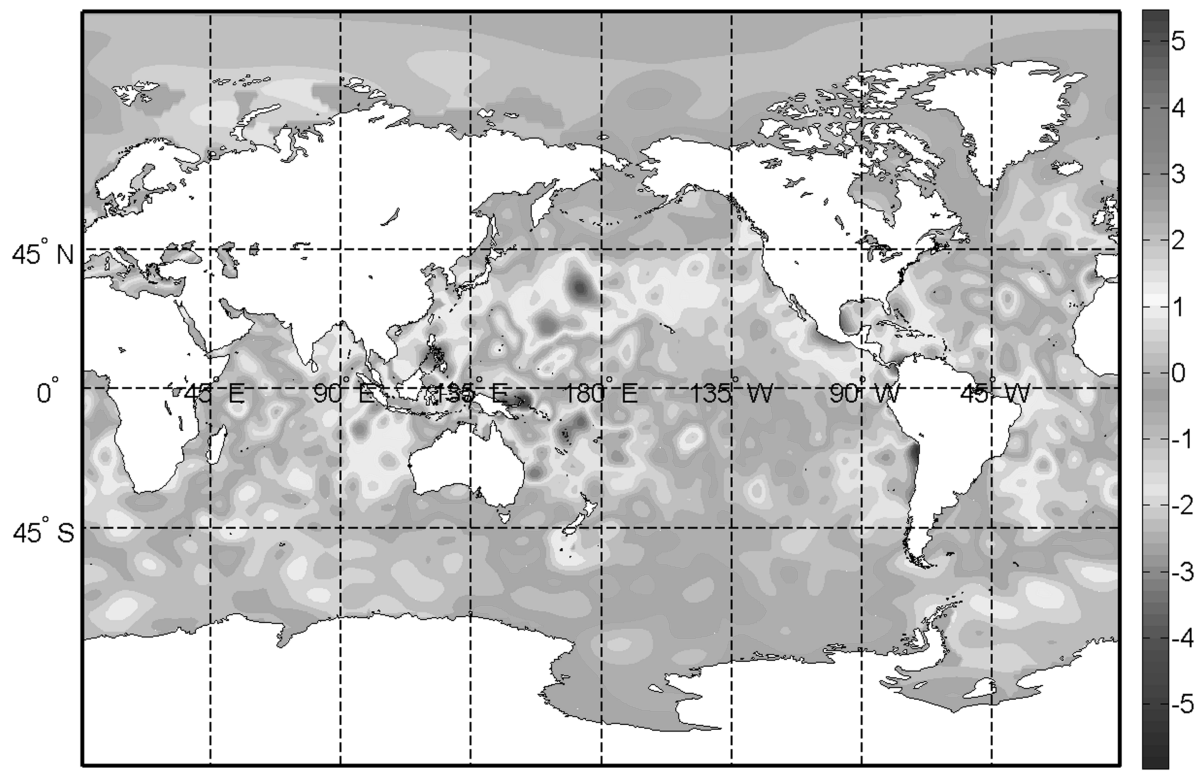

Fig. 5 The difference between the geoid undulations derived from the GOGRA04S model and satellite altimetry. (Unit: $\mathrm{m}$ )

\subsection{Moho depths versus MDT effects}

As the MDT is considered as a false gravity signal, it is important to figure out how much of this signal can affect the gravimetric determination of the Moho depth. This was carried out using the DNSC07MDT mean dynamic topography model derived by satellite altimetry (Andersen et al. 2010). The MDT generated gravity potential spherical harmonics are given by (cf. Sjöberg 1998a, b)

$$
c_{n m}^{M D T} \approx \frac{3 \rho_{w}}{\rho_{e}(2 n+1)}\left[\frac{(M D T)_{n m}}{R}+\frac{n+2}{2} \frac{\left(M D T^{2}\right)_{n m}}{R^{2}}+\frac{(n+2)(n+1)}{6} \frac{\left(M D T^{3}\right)_{n m}}{R^{3}}\right],
$$

where $(M D T)_{n m},\left(M D T^{2}\right)_{n m}$ and $\left(M D T^{3}\right)_{n m}$ are spherical harmonic coefficients of the $M D T$, to powers 1,2 and 3, respectively. $\rho_{e}$ and $\rho_{w}$ are the mean densities of the Earth's mass and oceanic water, respectively. The MDT effect on gravity according to Eq. (10) can be written as

$$
\Delta g^{M D T}=\frac{G M}{R} \sum_{n=0}^{\infty}\left(c_{n m}^{M D T}\right) Y_{n m}(P)
$$

where $G M$ is the geocentric gravitational constant. Subsequently, the MDT effect on the Moho depth by means of Eq. (11) can be approximated by (cf. Sjöberg 2009)

$$
T^{M D T} \approx-\frac{\Delta g^{M D T}}{2 \pi G \Delta \rho} .
$$


Table 3 Statistics of the MDT gravity and its effects on the Moho depth in ocean areas

\begin{tabular}{lllccr}
\hline Unit & Quantities & Max. & Mean & Min. & STD \\
\hline \multirow{2}{*}{\begin{tabular}{lllll} 
mGal \\
\multirow{2}{*}{ MDT }
\end{tabular}} & 1.79 & 0.18 & -1.96 & 0.61 \\
& $T^{M D T}$ & 4.99 & 1.71 & -1.01 & 0.79 \\
\hline
\end{tabular}

STD standard deviation of the estimated quantities over the ocean blocks, $\triangle g^{M D T}$ and $T^{M D T}$ are MDT effect on gravity and on the Moho depth, respectively

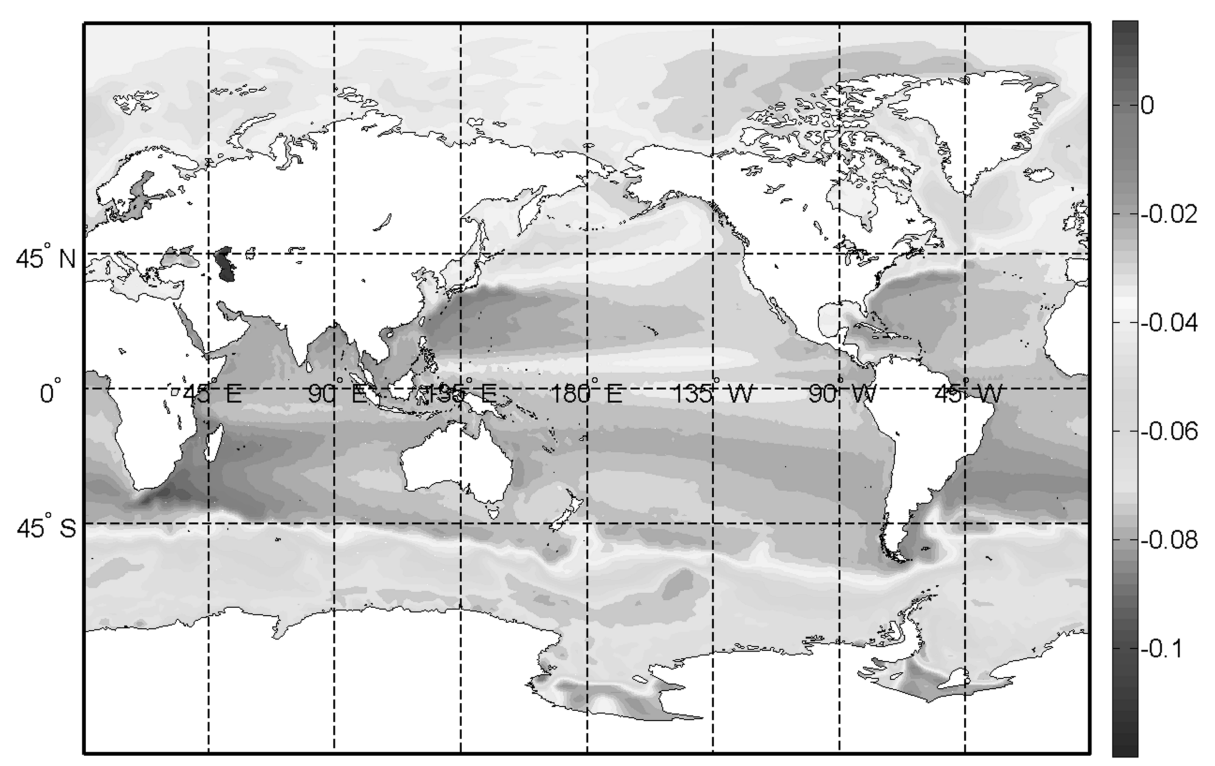

Fig. 6 The MDT effect on gravity. (Unit: mGal)

As we already mentioned the MDT yields a systematic error to the results. However, with reference to Table 3 and Figs. 6 and 7 one can see that the MDT effect on gravity (0.01 $\mathrm{mGal}$ in the STD) and on Moho depth $(0.79 \mathrm{~m}$ in the STD) versus the standard deviation of the estimated Moho depths (6 km in the STD) are not significant. Also, in order to answer the question why in this stage (Eq. 12) the planar approximation is used rather than the spherical approximation, one can observe that according to the obtained relative error for the MDT (10\% in RMS), the planar approximation provides a fast and relatively accurate way of calculating the effect of the MDT on the Moho depths. As a result, it can be concluded that even if the MDT effect is not well-corrected, it cannot affect significantly the estimated Moho depths.

\section{Conclusions}

The investigation presented in this study demonstrated that the VMM approach is in principle applicable for predicting Moho geometry using a global marine gravity field model and a solid DTM2006 topography model. The method has been applied successfully 


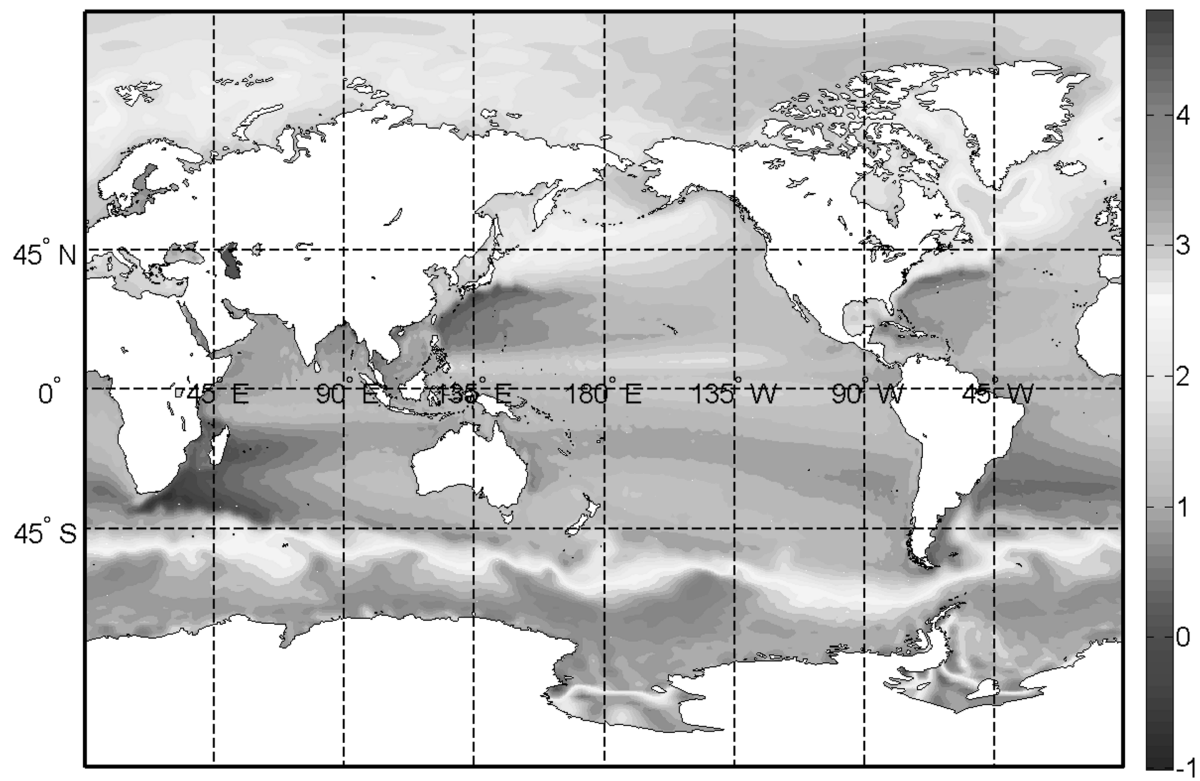

Fig. 7 The MDT effect on the Moho depth. (Unit: m)

over the oceans, where in most cases the only available primary observable with a dense coverage are observations from satellite altimetry.

The numerical results obtained show that the gravity disturbances estimated from satellite altimetry and a gravimetric satellite-only model agree to $11 \mathrm{mGal}$ in RMS. This result depends on the accuracy of the altimeter data, the data coverage and MDT effect. In order to figure out whether there is still some significant MDT effect left in the corrected altimetric geoid model, this model was directly compared to the satellite-only model over the oceans. This comparison yielded some significant differences mainly close to the Equator, which could be due to remnant MDT and/or errors in the radial position of satellite altimetry. Therefore, the considered correction for the MDT may still require improvements.

The numerical computations carried out for the Moho depth show $0.69 \mathrm{~km}$ in RMS agreement between our estimates and the independent GOGRA04S model. Also the Moho depths corrected for NIEs and the CRUST1.0 model agree to $2.2 \mathrm{~km}$ in RMS and with the GEMMA1.0 based model to $3 \mathrm{~km}$. Also we found that the MDT has no significant effect on the estimated Moho depth.

As can be seen from the numerical results, one factor that somewhat limits the quality of the outcomes is that the planar rather than the spherical Bouguer shell is used which supports the use of the spherical Bouguer shell in future studies. However according to the derived relative error for the Moho depth (2\% in RMS), one can say that the planar approximation could be a fast and relatively accurate way of calculating the Moho depth.

Acknowledgments This study was supported by projects Nos. 76/10:1 and 116/12 of the Swedish National Space Board (SNSB). Dr. Ole Baltazar Andersen from The National Space Institute of Denmark (DTU SPACE) is acknowledged for his help and discussion about the global marine gravity field model. 


\section{References}

Andersen OB, Knudsen P, Berry PA (2010) The DNSC08GRA global marine gravity field from double retracked satellite altimetry. J Geod 84(3):191-199

Bagherbandi M, Sjöberg LE (2012) Non-isostatic effects on crustal thickness: a study using CRUST2.0 in Fennoscandia. Phys Earth Planet Inter 200:37-44

Bagherbandi M, Sjöberg LE (2013) Improving gravimetric-isostatic models of crustal depth by correcting for non-isostatic effects and using CRUST2.0. Earth Sci Rev 117:29-39. doi:10.1016/j.earscirev.2012.12.002

Bagherbandi M, Tenzer R, Sjöberg LE, Novák P (2013) Improved global crustal thickness modeling based on the VMM isostatic model and non-isostatic gravity correction. J Geodyn 66:25-37

Bassin C, Laske G, Masters TG (2000) The current limits of resolution for surface wave tomography in North America. EOS Trans AGU 81:F897

Bouman J, Ebbing J, Meekes S, Abdul Fattah R, Fuchs M, Gradmann S, Bosch W (2013) GOCE gravity gradient data for lithospheric modeling. Int J Appl Earth Obs Geoinf 35:16-30

Deng X, Griffin DA, Ridgway K, Church JA, Featherstone WE, White NJ, Cahill M (2011) Satellite altimetry for geodetic, oceanographic, and climate studies in the Australian region. Coastal altimetry. Springer, Berlin, pp 473-508

Heiskanen WA, Moritz H (1967) Physical geodesy. W. H. Freeman, New York

Hwang C, Parsons B (1996) A optimal procedure for deriving marine gravity from multi-satellite altimetry. J Geophys Int 125:705-719

Janjić T, Schröter J, Savcenko R, Bosch W, Albertella A, Rummel R, Klatt O (2012) Impact of combining GRACE and GOCE gravity data on ocean circulation estimates. Ocean Sci 8(1):65-79

Laske G, Masters G, Ma Z, Pasyanos ME (2013), A new global crustal model at $1 \times 1$ degrees (CRUST1.0). (http://igppweb.ucsd.edu/ gabi/crust1.html)

Lebedev S, Adam JMC, Meier T (2013) Mapping the Moho with seismic surface waves: a review, resolution analysis, and recommended inversion strategies. Tectonophysics 609:377-394

Meier U, Curtis A, Trampert J (2007) Global crustal thickness from neural network inversion of surface wave data. Geophys J Int 169(2):706-722

Moritz H (1990) The figure of the Earth. H Wichmann, Karlsruhe

Moritz H (2000) Geodetic reference system 1980. J Geod 74:128-162

Pasyanos M, Masters G, Laske G, Ma Z (2012) Litho1.0 - an updated crust and lithospheric model of the Earth developed using multiple data constraints. Fall Meeting, AGU, San Francisco, Calif., Abstract: 3-7 Dec, 2012. 2.4

Rapp RH (1980) A comparison of altimeter and gravimetric geoids in the Tonga Trench and Indian Ocean areas. Bull Géod 54(2):149-163

Reguzzoni M, Sampietro D (2014) GEMMA: An Earth crustal model based on GOCE satellite data. Int J Appl Earth Obs Geoinf 35:31-43

Reguzzoni M, Sampietro D, Sansò F (2013) Global Moho from the combination of the CRUST2.0 model and GOCE data. Geophys J Int 195:222-237

Sampietro D, Reguzzoni M, Braitenberg C (2014) The GOCE estimated Moho beneath the Tibetan Plateau and Himalaya. Earth on the edge: science for a sustainable planet. Springer, Berlin, pp 391-397

Shapiro NM, Ritzwoller MH (2002) Monte-Carlo inversion for a global shear-velocity model of the crust and upper mantle. Geophys J Int 151:88-105

Sjöberg LE (1998a) The exterior Airy/Heiskanen topographic-isostatic gravity potential anomaly and the effect of analytical continuation in Stokes' formula. J Geod 72:654-662

Sjöberg LE (1998b) On the Pratt and Airy models of isostatic geoid undulations. J Geod 26(1):137-147

Sjöberg LE (2009) Solving Vening Meinesz-Moritz inverse problem in isostasy. Geophys J Int 179(3):1527-1536. doi:10.1111/j.1365-246X.2009.04397.x

Sjöberg LE (2013) On the isostatic gravity disturbance and disturbance and their applications to Vening Meinesz-Moritz gravimetric inverse problem. Geophys J Int 193(3):1277-1282

Tenzer R, Bagherbandi M (2012) Reformulation of the Vening-Meinesz Moritz inverse problem of isostasy for isostatic gravity disturbances. Int J Geosci 2012(3):918-929. doi:10.4236/ijg.2012.325094

Tenzer, R., Chen, W., Tsoulis, D., Bagherbandi, M., Sjöberg, L.E., Novák, P. (2014), Spectral and spatial characteristics of the refined CRUST1.0 gravity field. Submitted to Surveys in Geophysics

Vening Meinesz FA (1931) Une nouvelle methode pour la reduction isostatique regionale del'intensite de la pesanteur. Bull Geod 29:33-51

Watts AB (2001) Isostasy and flexure of the lithosphere. Cambridge University Press, Cambridge

Yi W, Rummel R, Gruber T (2013) Gravity field contribution analysis of GOCE gravitational gradient components. Stud Geophys Geod 57(2):174-202 